\title{
Expressões da desigualdade racial na política de previdência social: uma análise a partir do acesso a direitos previdenciários no município de Rolândia-PR
}

\author{
Expressions of racial inequality in social security policy: analysis based on access to social \\ security rights in the municipality of Rolândia-PR
}

\author{
Flávia Cristina Silva* \\ Olegna de Souza Guedes**
}

\begin{abstract}
Resumo:
O artigo apresenta resultados de pesquisa sobre o acesso da população negra aos direitos viabilizados pela política de previdência, no município de Rolândia-PR. Objetiva evidenciar que dificuldades nesse acesso, revelam uma das expressões da desigualdade racial no Brasil: a dificuldade de acesso aos direitos sociais viabilizados pela política de previdência, e que essa dificuldade é maior entre a população negra do que entre a população branca. Foi construído através de análise bibliográfica, análise documental e de dados sobre a demanda apresentada por homens e mulheres que procuraram agência do Instituto Nacional de Previdência Social (INSS), do município de Rolândia (PR). Esses dados foram colhidos através de formulários elaborados pelas pesquisadoras e preenchidos por sujeitos informantes, profissionais que trabalham nessa agência. Conclui-se que entre os trabalhadores negros registram-se maiores percentuais de informalidade e precarização de trabalho do que os que se observam entre os trabalhadores brancos; fato que se expressa em maiores índices de exclusão dos negros do excesso aos benefícios vinculados a uma política contributiva.
\end{abstract}

Palavras-Chave: Desigualdade racial. Racismo. Direitos. Previdência Social. Serviço Social.

\begin{abstract}
:
The article presents research results on the access of the black population to rights made possible by the social security policy, in the city of Rolândia-PR. It aims to show that difficulties in this access reveal one of the expressions of racial inequality in Brazil: the difficulty of access to social rights made possible by social security policy, and that this difficulty is greater among the black population than among the white population. It was constructed through bibliographical analysis, documentary analysis and data on the demand presented by men and women who sought agency of the National Social Security Institute (INSS), in the city of Rolândia (PR). These data were collected through forms developed by the researchers and filled by informants, professionals working in this agency. It concludes that among black workers there are higher percentages of informality and precariousness of work than those observed among white workers; a fact that is expressed in higher exclusion rates of blacks from excess to benefits linked to a contributory policy.
\end{abstract}

Keywords: Racial inequality. Racism. Rights. Social Security. Social work.

\footnotetext{
* Doutora em Serviço Social pela Pontifícia Universidade Católica de São Paulo. Docente do Curso de Graduação em Serviço Social e do Programa de Pós Graduação em Serviço Social e Política social da Universidade Estadual de Londrina.

** Graduada em Serviço Social pela Universidade Estadual de Londrina.
} 


\section{Introdução}

O artigo que ora apresenta-se é resultado de uma pesquisa qualitativa, construída durante três anos, no período de iniciação científica de uma das autoras. A primeira etapa da pesquisa, construída a partir de referências bibliográficas sobre a desigualdade racial, permitiu entender e partilhar das interpretações que afirmam que tal desigualdade é um fenômeno complexo, uma vez que se configura como uma das mediações da dominação-exploração do modo de produção capitalista, e que tem, como uma de suas formas de materialização o racismo.

A segunda etapa da pesquisa foi construída, também, a partir de pesquisa bibliográfica e, além dessa, de pesquisa documental. Esta última teve como fonte os seguintes bancos de dados oficiais referente ao acesso da população negra a direitos fundamentais:IBGE- Instituto brasileiro de geografia e estatística, PNAD- Pesquisa nacional por amostra de domicílios, IPEA- Instituto de Pesquisa EconômicaAplicada, SEPPIR- Secretaria de Políticas de Promoção da Igualdade Racial e em documentos legais como a Constituição Federal de 1988, Estatuto da Igualdade Racial e Lei 8.213. Esta etapa permitiu observar que uma das expressões da desigualde racial no Brasil é o ascesso desigual ao mercado de trabalho formal aos homens e mulheres brancos(as) e negros(as). Esse fato despertou para a necessidade de uma terceira etapa para a pesquisa, cujos resultados são apresentados nesse artigo.

O artigo trata, então, da sistematização de dados colhidos nesta terceira etapa da pesquisa e que se referem ao acesso da população negra aos direitos vinculados à política de previdência. Como uma das etapas de uma pesquisa de caráter qualitativo, a orientação para a coleta desses dados obedeceu a critérios dessa modalidade de pesquisa. Foram colhidos a partir de um modelo de formulário construído pelas pesquisadoras e entregue as assistentes sociais que trabalham em uma agência do INSS situada em município de médio porte do Estado do Paraná, Rolândia. Mediante autorização do órgão, o formulário foi reproduzido por estas profissionais e utilizado, para coleta dos dados empíricosdesta pesquisa.Ele contém dados que se referem ao perfil socioeconômico, identificação básica (como sexo, faixa etária e raça) e, também, que traduzem as principais demandas apresentadas pelos usuários que procuraram pelo acesso ao direito previdenciário pela primeira vez, através do atendimentorealizado pelas assistentes socias. Denomina-se, então, estas assistentes sociais de sujeitos informantes dessa pesquisa. 
Os dados foram colhidos no período de outubro de 2016 a janeiro de 2017; conforme sugestão das pesquisadoras, diante de ajustes necessários entre o cronograma da pesquisa e readequações no calendário acadêmico daUniversidade a que elas estavam vinculadas.

No que se refere à escolha para local de aplicação da pesquisa, a agência do INSS do município de Rolândia, o critério utilizado foi à acessibilidadee o apoio das profissionais da referida agência que se dispuseram, prontamente. Optou-se assim, neste artigo, por apresentar partes das reflexões e contribuições desta pesquisa em dois subitens. O primeiro, a seguir, refere-se aos aspectos sócio-históricos da desigualdade racial no Brasil, necessários para a análise da expressão da desigualdade do acesso aos direitos viabilzados pela política de previdência, entre dois grandes grupos populacionais: os brasileiros brancos e os brasileiros negros. O segundo, apresenta e analisa os dados da demanda por acesso à política de previdência no município de Rolândia, nos quais sinalizam-se aspectos que evidenciam particularidades apresentadas por homens e mulheres negro(as) em relação aos brancos.

\section{Aspectos Sócio-Históricos da Desigualdade Racial no Brasil: Impactos sobre o Acesso da População Negra aos Direitos Previdenciários}

O Brasil é um país fortemente marcado pelas desigualdades sociais, e essa desigualdade possui particularidades e fatores estruturantes; um deles é o racismo. O País possui uma grande concentração de renda e consequentemente de uma abismal desigualdade de acesso aos bens e riquezas nele produzidos. Contudo, quando essa desigualdade é analisada levando em consideração indicadores como a cor/raça torna-se ainda fica mais evidente. Uma pequena elite que concentra a maior parte da riqueza no País é essencialmente branca, enquanto a população pobre e miserável do País é, em sua maior parte, negra.

Dados do IBGE (2015), retirados da publicação "Síntese de Indicadores Sociais: uma análise das condições de vida da sociedade brasileira de 2015", indicam que a desigualdade de rendimentos segundo cor ou raça da população aparece de forma mais acentuada na população que se identifica como de cor ou raça preta ou parda. Esta população representava $76,0 \%$ das pessoas com menores rendimentos da população (10\%) e 17,4\% das pessoas com menores rendimentos (1\%) em 2014. É importante ressaltar, que houve uma elevação da participação de pretos e pardos no topo da distribuição de renda, que em 2004 era de 12,4\% e em 2014 atinge 17,4; mas, ainda persiste uma diferença muito grande em relação àqueles que se declaram brancos, que compunham $80 \%$, com os maiores rendimentos em 2014 . Esse dado deve ser analisado também, em seu contrate com a composição geral da população, haja 
vista que em 2014 a população declarada preta ou parta atingiu 53,6\%, ou seja, mais da metade da população brasileira (IBGE,2015).

Mesmo com aparentes melhorias no padrão de consumo da população pobre no País, proporcionadas com a implantação de políticas públicas de proteção social, entendemos, com base nas contribuições de Ciconello (2008), que ainda subsiste grande desvantagem da população negra em relação à população branca em todos os aspectos, no que tange ao acesso aos bens de consumo e direitos fundamentais. Para esse autor, a assimetria entre negros e brancos se manifesta, também, nas relações interpessoais construídas no cotidiano e, sobretudo na dificuldade de acesso aos bens e serviços, ao mercado de trabalho, ao ensino superior, exercício dos direitos civis, políticos, sociais e econômicos (CICONELLO,2007).

Não há como entender a causa e persistência dessa desigualdade, sem buscar os marcos históricos que originaram e a perpetuaram. Sua gênese está no passado de escravidão ${ }^{1}$ e invisibilidade da população negra que subsiste até a contemporaneidade. Após a abolição da escravatura, não fez parte da agenda política do Estado qualquer medida protetiva ou que visasse garantir aos negros e negras condições de mobilidade social; pelo contrário, o Estado adotou medidas que os(as) mantiveram em condição de desvantagem em relação à elite branca (NEDER, 1994).Um dos fatos que revelam estas medidas é o que se evidencia um ano após a abolição; ou seja, quando o Brasil é proclamado como República; sistema idealmente fundado na igualdade e liberdade no qual todos os homens passam a adquirir o status de cidadão livre. Contudo, adota-se, por parte do Estado, mecanismos que mantiveram a diferenciação entre cidadãos com base na sua cor de pele justificados através do discurso do "racismo científico".

Tal racismo consistia em um conjunto de teorias formuladas por cientistas europeus e norte-americanos para justificar a dominação ideológica de grupos étnicos brancos que defendiam a tese da inferioridade biológica dos não brancos. Foi amplamente utilizado no Brasil para legitimar a opressão contra os negros, naturalizar a desigualdade racial e estabelecer uma hierarquia social (THEODORO, 2008) e, no Estado Brasileiro, é combinada com a adoção de uma política de migração que agregava dois grandes objetivos: substituir a mãode obra negra, após a abolição da escravidão e promover o branqueamento da população brasileira, um propósito que revela "uma forma de conciliar a crença na superioridade branca

\footnotetext{
${ }^{1}$ Neste estudo, referimos à escravização do negro, embora o país tenha adotado, ao longo de sua história, diversas formas de escravidão, a exemplo dos indígenas; imigrantes que vinham trabalhar nas lavouras brasileiras, já no século XX.
} 
com a busca do progressivo desaparecimento do negro." (JACCOUD, 2008, p. 53). A defesa desse propóstio expressa a preocupação em criar uma identidade nacional que excluísse da história do Brasil as referências negras na construção social do País e tivesse a branquitude como referência. Para isso, um dos investimentos do Estado foi a política de imigração, uma forma de substituição da mãodeobra escrava e para promover o branqueamento do País.

Assiste-se, então, à consolidação de uma República em que negros e indígenas são relegados a cidadãos de segunda classe; considerados inferiores e incapazes de contribuir para o desenvolvimento nacional. As desigualdades existentes não eram interpretadas como fruto do contexto social, político e econômico de opressão e desigualdade de oportunidades, mas como diferenças provenientes da raça. Cresce no País a defesa da hierarquização das raças, tendo a branca como modelo de perfeição e superioridade. Idealiza-se o desenvolvimento do País à branquitude(JACCOUD, 2008).

Apesar desse ideário de branqueamento associado ao fomento à imigração, os negros até o século XIX, cumpriam um papel central na economia brasileira, já que eram a principal força de trabalho utilizada em todas as atividades do país (COSTA, 1999). Observase, entretanto, que desde 1850, com a Lei Euzébio de Queiroz, que proibiu o tráfico negreiro, uma alteração do perfil da mãodeobra no Brasil. Paulatinamente, os imigrantes europeus ocupam, de forma crescente, funções que antes eram exercidas pelos negros, e os ex-escravos vão se juntar à massa dos homens livres e libertos, que sem espaço no mercado vão se inserir ou na economia de subsistência, ou em atividades mal remuneradas.

A formação do mercado de trabalho no Brasil foi, portanto, marcada por uma ideologia racista, excludente e orientada pela política do branqueamento (THEODORO, 2008). Sob este ideário, natransição de uma economia escravocrata para uma economia de mercado, ao mesmo tempo em que se criou um mercado de trabalho livre, criou um excedente estrutural de trabalhadores formado por indígenas, pobres, negros e seus descendentes. Estes, sem espaço no mercado formal,irão desenvolveratividades, informais, marginais, precárias e mal remuneradas, e, sofrendo toda classe de violações de direitos.

A partir do período de 1920 e 1930, a combinação dos efeitos da imigração europeia e da miscigenação começam a mostrar seus efeitos; "as elites percebiam a questão racial de forma cada vez mais positiva: para eles, o Brasil parecia branquear-se de maneira significativa, e o problema racial se encaminhava para uma solução." (JACCOUD, 2008, p. 54). O conceito de raça, conforme a autora, perde força na interpretação da sociedade brasileira e a desigualdade racial deixa de ser explicada pelo discurso das diferenças biológicas e passa a ser 
explicado pela dimensão social e cultural. A questão racial passa a ser encarada sob a roupagem do mito da democracia racial. Um mito que vai trazer uma nova chave de interpretação da sociedade brasileira "a ideia de raça foi gradativamente dando lugar, nas Ciências Sociais, à ideia de cultura, e o ideal de branqueamento foi ultrapassado, em termos de projeto nacional pela afirmação e valorização do povo brasileiro." (JACCOUD, 2008, p.56).

A narrativa de que o Brasil é fruto do encontro das três raças, um país genuinamente mestiço; portanto um país de identidade homogênea marcado pela integração e harmonia social, se nega constatar a existência de várias identidades étnicas. Durante o período da ditadura, esse mito da democracia racial se transforma em dogma, sendo utilizado como uma espécie de ideologia do Estado brasileiro, que negava a todo custo à existência do racismo no Brasil.

A propagação do mito da democracia racial no imaginário social dificulta, ainda mais, a pensar o trato da desigualdade racial, porque torna o racismo e as expressões da desigualdade racial imperceptíveis (THEODORO, 2008). Ele serviu como mecanismo para neutralizar a discussão da questão racial no Brasil, pois cria a sensação de que não temos conflito racial e, se não temos, não precisamos discutir sobre, nem promover nenhuma ação para solucioná-lo. A legitimação desse discurso, automaticamente, transformou os negros que ousavam lutar ou denunciar o racismo em criminosos e desordeiros que incitavam o conflito racial. Essa imagem do Brasil como paraíso racial começou a atrair a atenção e curiosidade dos países estrangeiros. Registra-se uma grande iniciativa internacional voltada a conhecer como o Brasil, um país tão miscigenado, conseguia lidar com toda essa diversidade cultural sem gerar conflitos. Refere-se, aqui, à iniciativa da UNESCO-Organização das Nações Unidas para a Educação, a Ciência e a Cultura, que em 1950, encomenda uma pesquisa sobre as relações raciais no Brasil. A pesquisa foidesenvolvida pela USP-Universidade de São Paulo e foram convidados pararelializá-la pesquisadores brasileiros: Florestan Fernandes, Octávio lanni, Oracy Nogueira, Fernando Henrique Cardoso, Roger Bastide, Luiz Costa Pinto, Thales de Azevedo. Estes chegaram as conclusões que, no Brasil existiam sérios problemas de racismo e uma clara desigualdade social entre negros e brancos (COSTA, 2010). Por mais que no plano teórico essa pesquisa tenha desmontado o mito da democracia racial, por um bom tempo esse desvelamento ficou restrito ao plano da academia, uma vez que logo se instaurou a ditadura no Brasil (1964) que novamente calou a discussão sobre a questão racial no País. Segundo Guimarães (1999, p. 63-64), durante o período da ditadura o mito da democracia 
racial se transforma em dogma, sendo utilizado como uma espécie de ideologia do Estado brasileiro, que negava a todo custo a existência do racismo no Brasil,

\begin{abstract}
No entanto, a falta de politicas públicas efetivas para reverter a situação marginal dos negros na sociedade brasileira acabou por reproduzir a ordem hierárquica diferenciadora entre brancos e negros, ampliando as desigualdades sociais e nutrindo uma série de tropos para a raça. Foi justamente em sua função obscurecedora e manipuladora que o anti-racismo, neste país, passou a incomodar, cada vez mais, a população negra, sobretudo aquela fatia que não queria ser benevolamente embranquecida por nossa terminologia cromática - aqueles para quem palavras como "escuros", "morenos", "roxinhos" e tantas outras eram percebidas como uma desvantagem. A tensão entre um ideário anti-racista que, corretamente, negava a existência biológica das raças e uma ideologia nacional, que negava a existência de racismo e de discriminação racial, acabou por se tornar insuportável para todos e insustentável pelos fatos.
\end{abstract}

Apenas a partir do final da década de 1970 e na década de 1980, a questão racial volta em cena, trazida pelo movimento negro que ganha força no bojodo processo de redemocratização do país (CICONELLO, 2008). O ano de 1988 é um marco importante para o debate racial por ser o ano de promulgação da Constituição Federal de 1988, na qual, pela primeira vez o Estado brasileiro reconhece o racismo como um problema nacional e adota na constituição formas de enfrentá-lo "no âmbito dos princípios (igualdade de direitos), da legislação penal (com criminalização das práticas de racismo) e da cultura (com reconhecimento da influência negra na formação do Brasil)." (CICONELLO, 2008, p. 9).

Na década de 1980, e principalmente 1990, a organização do Movimento Negro ampliou o debate sobre a questão racial contestando duramente o mito da democracia racial. Sua combatividade conseguiu pressionar o Estado brasileiro a adotar medidas práticas de enfrentamento ao racismo, dentre as quais destacamos: a criação da Fundação Palmares (1995); A criação do Grupo de Trabalho Interministerial de Valorização da População Negra (GTI População Negra), em 1995; a Participação do Brasil na III Conferência Mundial contra o racismo em Durban (2001); a criação do Conselho Nacional de Combate à Discriminação (2001); a criação da SEPPIR- Secretaria Especial de Políticas de Promoção da Igualdade Racial e o CNPIR- Conselho Nacional de Promoção da Igualdade racial, criado no governo Lula em 2003. Destacamos também:a Lei 10.639/ 2003 que inclui no currículo obrigatório das escolas o ensino da história e cultura afro-brasileira (CICONELLO, 2008); a Lei 12.711/ 2012 que institui o sistema de cotas nas universidades federais e Lei 12.288/2010 que institui o Estatuto da Igualdade racial. São marcos que destacam a concepção do racismo como produto social e histórico a ser enfrentado pela via das políticas públicas, por mais que haja toda uma 
problematização sobre a abrangência e eficácia dessas políticas. Contudo, a desigualde racial ainda se expressa de diferentes formas na sociedade brasileira. Entre estas, destaca-sea que se revela no acesso aos direitos previdenciários, como apresentado no item a seguir.

\section{O Acesso dos Negros aos Direitos Previdenciários no Município de Rolândia-PR}

O município de Rolândia, de acordo com dados do IBGE (2016), tem uma população estimada de 64.028 habitantes. Quanto à composição racial, temos um total de 39.205 habitantes brancos, o que corresponde a 61\% da população. Pretos são 3.055 e pardos 14.540, somando 17.595; ou seja, $27 \%$ de sua população é negra, 986 são amarelos, representando 1,53\% da população e 76 são indigenas, representando 0,11\% da população (IBGE, censo $2010)^{2}$

Esses dados da composição étnica da população do município de Rolândia não acompanham a média nacional. A região sul, por ser uma região que teve forte presença de uma colonizaçao europeia, apresenta uma concentração menor de negros e indígenas,se comparadaàs outras regiões no País e à média nacional. Conforme dados do IBGE de 2014, sobre composição da população brasileira por cor/raça, 45,5\% da população é branca e 53,6\%, mais da metade, da população brasileira, é negra (NEGROS..., 2015) Contudo, o fato desse percentual de negros no Município ser baixo em relação ao da população brancanão interfere nos resultados da pesquisa, uma vez que nosso propósito era, fundamentalmente, analisar as demandas apresentadas pelos que procuravam a agência do INSS dessa região para atendimento com vistas a identificar se elas apresentavam peculiariadades diferentes entre dois grandes grupos populacionais: os brancos e os negros.

A pesquisa empírica foi construída através da análise de formulários preenchidos pelos sujeitos informantes (assistentes sociais que trabalham no INSS no município de Rolândia ${ }^{3}$ ), com dados de 33 usuários da Política de Previdência, que procuraram por atendimento nesta agência do INSS com vistas a obter informações; dar entrada ou acompanhar o andamento da tramitação de seus direitos previdênciários, no período de outubro de 2016 a janeiro de 2017.

\footnotetext{
${ }^{2} \mathrm{O}$ último censo realizado pelo IBGE no município de Rolândia foi no ano de 2010, trabalhou-se apenas com os dados do IBGE, já que não foi encontrado dados atualizados sobre a população do município em outas fontes.

${ }^{3} \mathrm{~A}$ pesquisa foi aplicada após consentimento da gerência da agência do INSS que foi o lócus da pesquisa e cuidados éticos como: assinatura de termo de livre consentimento e preservação da identidade dos sujeitos da pesquisa.
} 
Nesse período, haja vista o intervalo de recesso de Natal, apenas 33 pessoas procuraram a agência com demandas previdenciárias que chegaram até os assistentes sociais. Dentre estas, $27 \%$ são do sexo masculino e $73 \%$ do sexo feminino; $45 \%$ se autodeclararam como negros e $55 \%$ como brancos. Este fato já é relevante para a pesquisa. Num Município em que apenas $27 \%$ da população é negra, a demanda pelo trabalho dos assistentes sociais é apenas $10 \%$ menor que a dos brancos; haja vista que esta demanda se caracteriza, conforme quadros nas páginas 17 e 18, por orientações sobre o acesso aos direitos fundamentais, ou como forma de materializar tais direitos mínimos, como o BPC (Benefício de Prestação continuada).

Dentre esses 15 negros, registram-se as seguintes autodeclarações: 33\% consideramse negros; $20 \%$ consideram-se pardos, $40 \%$ consideram-se morenos; $7 \%$ considera-se moreno claro. Nesta pesquisa, optou-se por denominar estas pessoas de sujeitos, uma vez que através delas teve-se o acesso às informações necessárias para concretizar asanálises sobre o objeto pesquisado. A obtenção desta autodeclaração se deu através de entrevista, na qual as assistentes sociais perguntaram a esses sujeitos como eles se declaram, de acordo com sua cor de pele. Cientes das dificuldades que existem no Brasil, devido a miscigenação e o colorismo, de que as pessoas têm em identificar sua cor/ raça; solicitamos às profissionais que além da autodeclaração dos sujeitos, também fosse anotado a percepção que elas tinham desses sujeitos. Esta orientação foi uma forma de identificar se há alguma divergência ou dúvida por parte desses sujeitos declararem a cor da pele, no entanto, a informação considerada na pesquisa é a autodeclaração dos sujeitos. Segundo observações anotadas pelos sujeitos informantes da pesquisa, as assistentes sociais, constatou-se divergência na informação em $12 \%$ dos declarantes negros; fato que menos frequente entre os brancos. Estes, quando questionados sobre sua cor, não se utilizaram termos ou categorias intermediárias como ocorreu com os negros; ao contrário, em sua grande maioria, foram precisos em definir sua cor como branca.

Quanto à escolaridade dos sujeitos da pesquisa, observa-se um baixo grau de escolarização entre os dois grupos. Em sua maioria, esses sujeitos tem a faixa de escolaridade concentrada no Ensino Fundamental I e II, conforme ilustram os gráficos abaixo: 
Gráfico 1- Escolaridade brancos e negros.
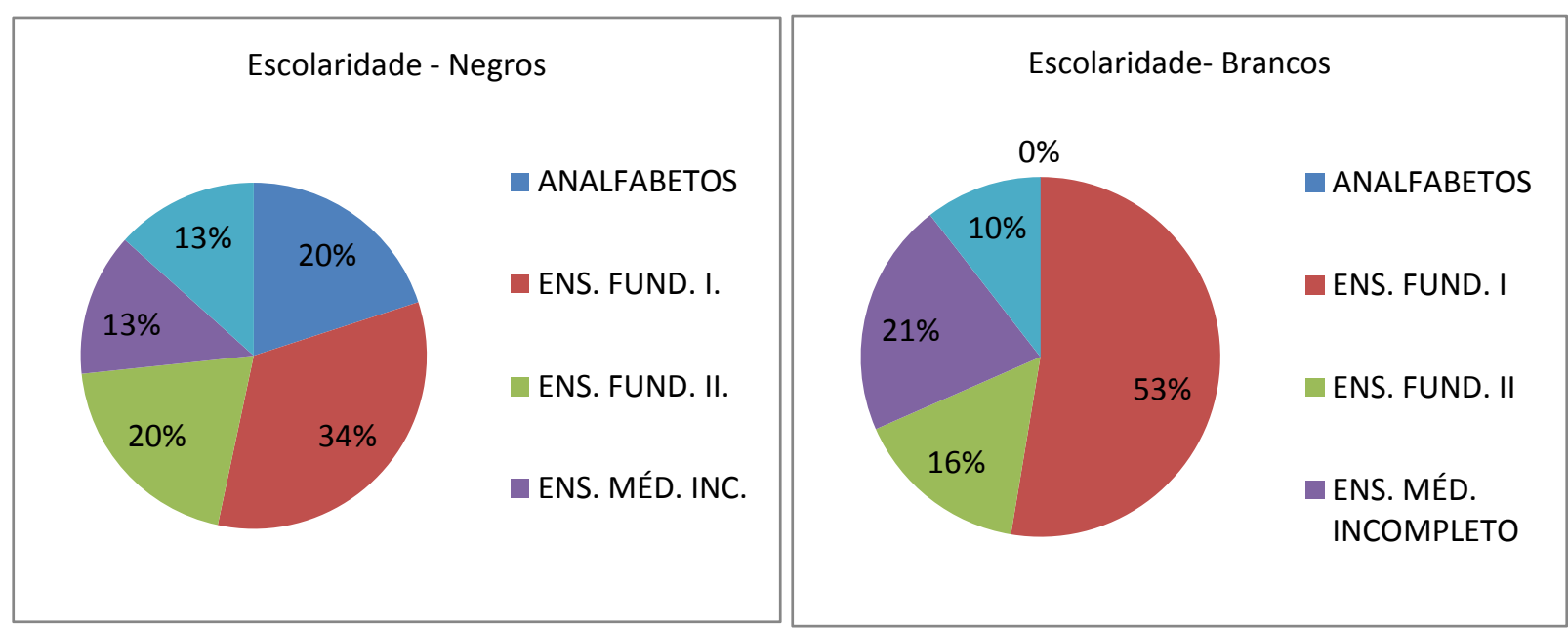

Fonte: Próprias autoras, 2017

Observa-se que, dentre os brancos, não há analfabetos. Da mesma forma, no que tange ao ensino fundamental e médio incompleto, os sujeitos que estão entre a população branca, também possuem uma condição melhor que os sujeitos que estão entre os negros. Contudo, no ensino médio completo, o percentual de negros aparece um pouco maior que o dos brancos; dado que se torna irrelevante quando se volta ao total da amostragem de ambos os grupos; haja vista que em ambos os grupos, apenas $6 \%$ dos sujeitos relataram ter o ensino médio completo; mas o universo de negros totalizou 15 sujeitos e o universo de brancos 18 sujeitos.

Gráfico 2 -Escolaridade comparada brancos e negros

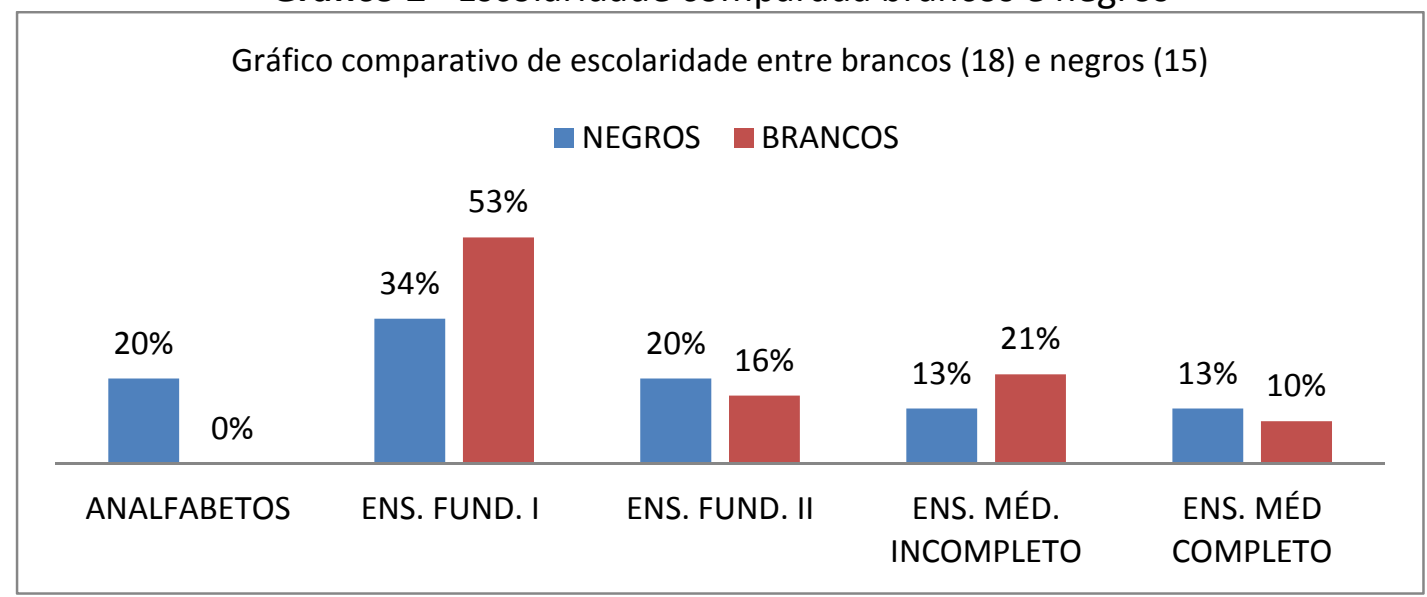

Fonte:Próprias autoras, 2017 
A escolaridade é um indicador importante para o acesso ao mercado de trabalho. Os dados dessa pesquisa acompanharam indicadores nacionais que revelam desvantagem na formação escolar da população negra em relação à população branca:

Gráfico 3 - Escolaridadenegros e brancos no Brasil

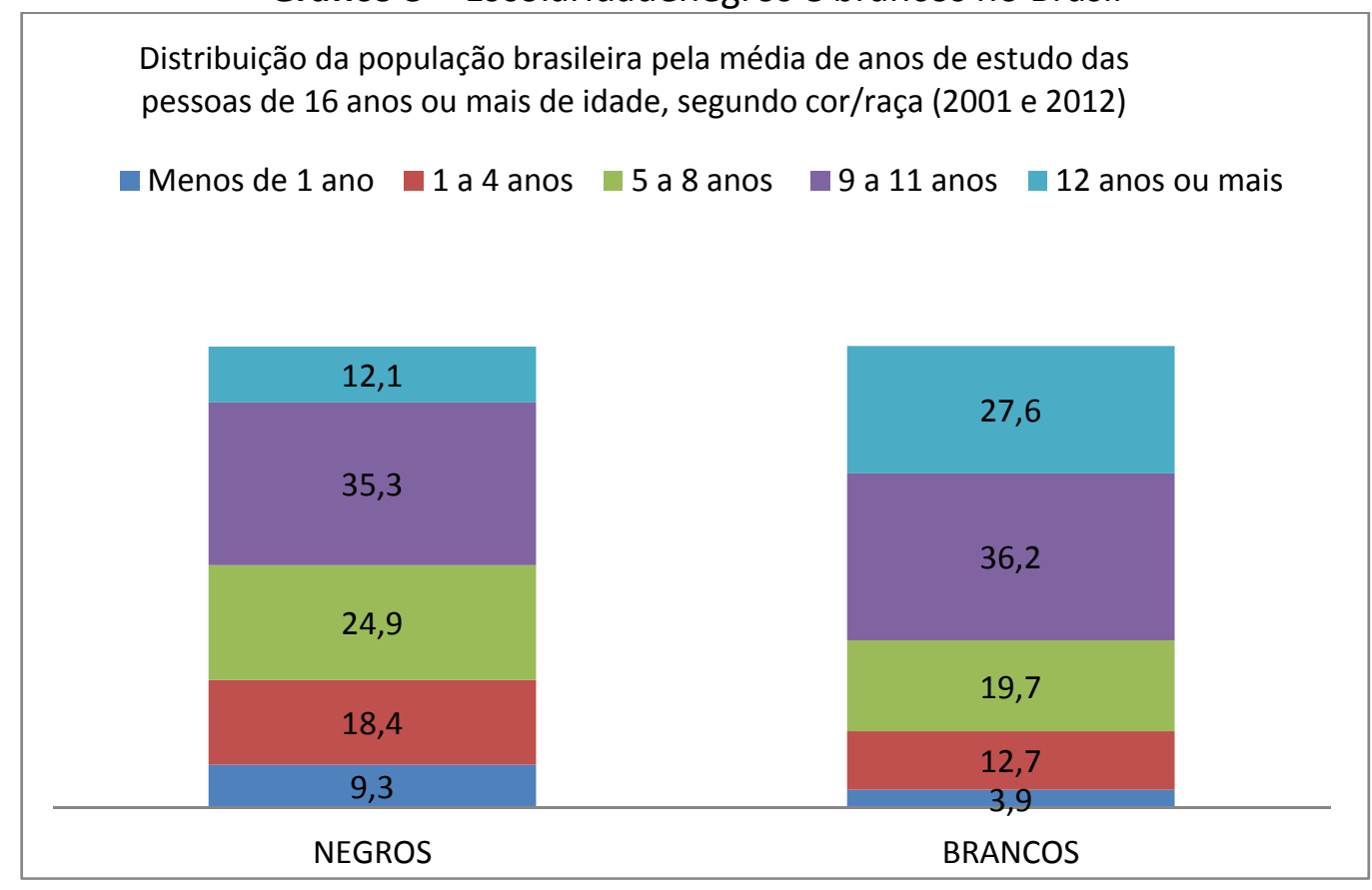

Fonte: IBGE.Microdados da PNAD (2011-2012)

Na base da pirâmide, que representa menos anos de estudo, o negro está mais representado, quando chega no topo da pirâmide que representa aqueles que possuem 12 anos de estudo ou mais, o negro tem menos da metade de representação que o branco.

Com relação à renda dos sujeitos, a situação dos dois grupos é semelhante e revela a condição de empobrecimento dos trabalhadores atendidos na agência do INSS de Rolândia. Dentre os 33 sujeitos que participaram da pesquisa, 52\% declararam não possuir renda pessoal, o que representa metade dos sujeitos que compõem a amostra. Entre os quedeclararam renda, a média gira entre 1 a 2 salários mínimos. Entre os negros: 8 sujeitos possuíam renda e 7 não a possuíam. Dentre esses sujeitos que declararam possuir renda:4são homens e 4são mulheres. Contudo, essas mulheres possuíam menor renda que os homens e, dentre os 5 homens entrevistados, apenas 1 não possuía renda; deste grupo:3possuíam renda proveniente de benefícios (BPC, aposentadoria, pensão por morte).

Entre os brancos: 8 possuíam renda pessoal e 10 não possuíam renda. Dentre os que possuiam: 5 eram mulheres e 3 eram homens. Na análise desse dado, cabe considerar que esse universo é composto mais por mulheres do que homens: 14 mulheres e 4 homens. Dentre 
esses 4 homens, três 3 possuíam renda e apenas 1 não possuía. Os homens brancos também possuem rendimentos maiores que as mulheres. Desta maneira, constatou-se que a ausência de renda atinge mais as mulheres do que os homens.

$\mathrm{Na}$ análise da renda, a situação dos dois grupos, brancos e negros, é semelhante; ou seja, não refletiu a realidade nacional na qual os salários dos negros é, em média, menor que a dos brancos ${ }^{4}$. No entanto, duas situações chamaram a atenção: entre os negros havia uma mulher com renda pessoal inferior a um salário mínimo ( $R \$ 400,00)$; e, entre os brancos, um homem com renda superior a 2 salários mínimos $(R \$ 5.000,00)$. São dois extremos que exemplificam àdesvalorização da mulher negra, no que tange à faixa salarial e a tendência à valorização dos homens brancos, tal como se evidencia nas estatísticas nacionais.

Se quanto à renda não há muita disparidade entre os dois grupos, as condições de inserção de classe tornam-se mais evidentes quando analisadosos dados referentes à profissão e empregabilidade. Entre os negros, 13\% sequer identificaram a profissão que exercem; apenas limitaram-se a dizer que são desempregados.

Outro fato é a nítida diferença entre a oportunidade de profissionalização para os negros e para os brancos. Observou-se que $27 \%$ são domésticas e $20 \%$ ajudantes gerais entre os negros; dados que apresentaram menores percentuais entre os brancos: $20 \%$ dométicas e $6 \%$ ajudantes gerais. Por outro lado, há entre os brancos, uma maior variedade de profissões, ainda que mal remuneradas, mas, ainda assim, com maior possibilidade de inserção no mercado formal de trabalho quando comprada aos negros. Há, também, um número de mulheres brancas que se declararam do lar (5) em relação às mulheres negras (1) que estão nesta condição.

${ }^{4}$ Conforme dados estatísticos da PNUD (2001-2010), disponível na publicação do IPEA (2014). 
Gráfio 4- Profissão dos negros

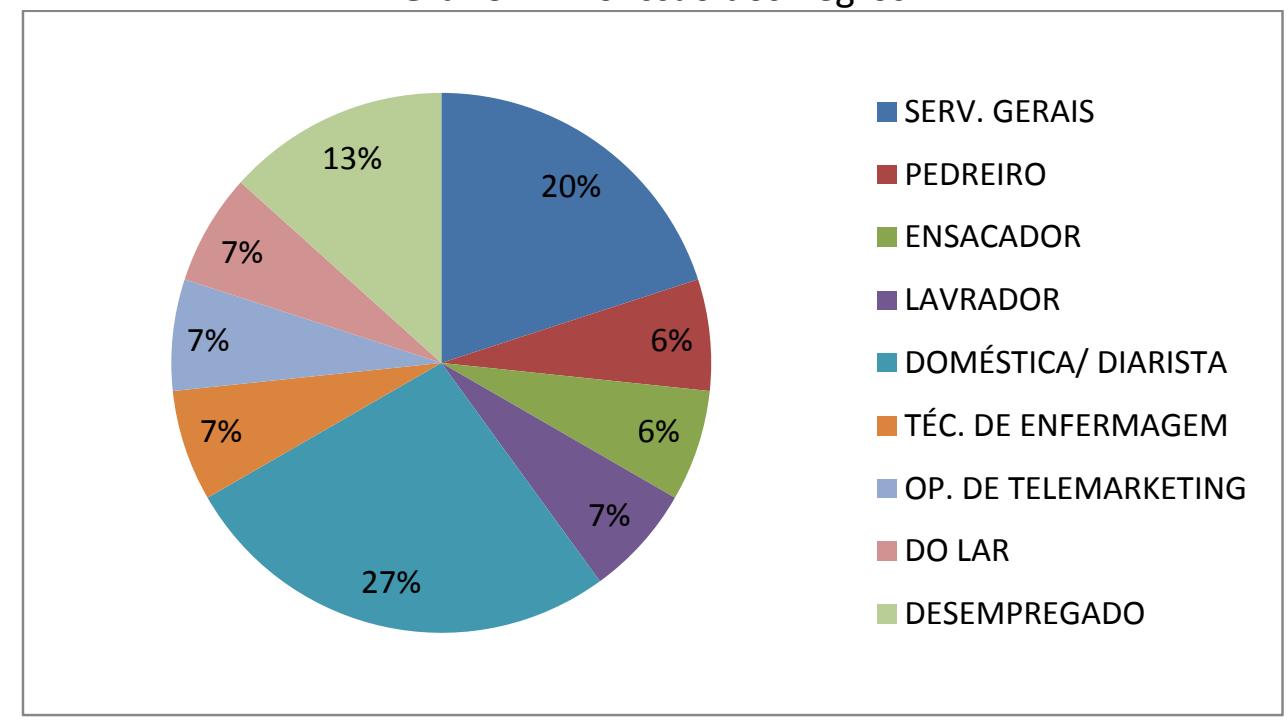

Fonte: Próprias autoras, 2017

Gráfico 5 - Profissão dosbrancos

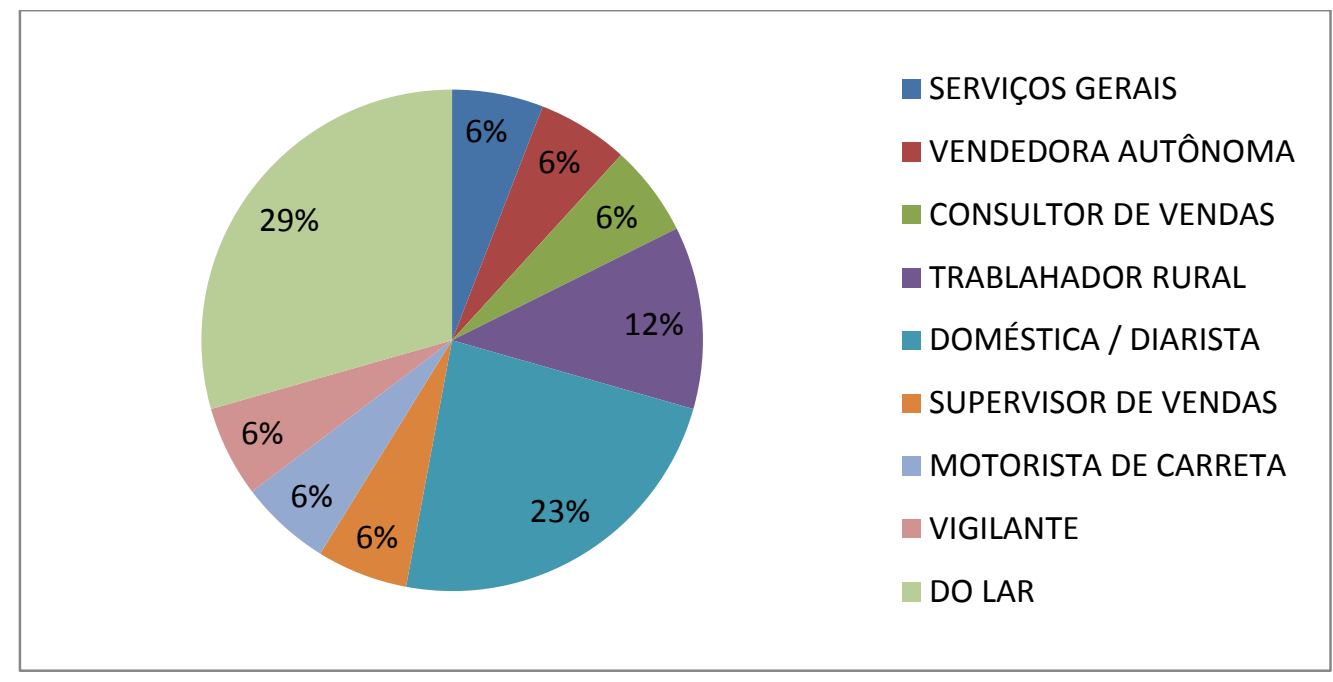

Fonte: Próprias autoras, 2017

A análise dos gráficos de profissão e tipo de atividade exercida mostra que a população negra está mais propensa a trabalhar em atividades braçais e não especializadas do que a população branca.Pode-seinferir, que um dos motivos refere-se ao fato do grau de escolarização da população negra ser um pouco menor em relação aos brancos; contudo, os relatos anotados pelas assistentes sociais, que foram os sujeitos informantes dessa pesquisa, evidenciam que tal formação não diminui o risco da informalidade, fato que foi evidenciado em relatos de dois sujeitos da pesquisa que são negros. Um deles contou sobre sua dificuldade de colocação em melhores posições no mercado de trabalho, mesmo possuindo qualificação: 
Ensino fundamental II completo, curso de Mecânico de manutenção de máquinas industriais no SENAI e Segurança patrimonial. Contou que já entregou currículo em várias empresas e sempre se informa sobre vagas na Agência do Trabalhador, mas ainda não conseguiu uma oportunidade para atuar nessa função. Atualmente, oferece seu trabalho no mercado informal, trabalha como ensacador (movimentador de mercadoria em abatedouro de aves). O outro relata que foi vítima de preconceito desde o período da escola e que já teve tentativas frustradas de ingresso no mercado de trabalho e que acredita terem relação com o fato de ser negra. Exemplifica que, certa vez, foi a uma loja concorrer a uma vaga de emprego, ao chegar no local foi vitíma de descaso e deboche direcionados a sua aparência física.

Jaccoud (2008), se reportando aos estudos de Hasenbalg e Silva (1992), discute sobre as dificuldades de ascenção social e inserção dos negros no mercado de trabalho. Explica que o processo de competição social ocorre por etapas e os negros durante esse processo vão acumulando desvantagens que impedem a igualdade de chances, e que a cor é um critério de seleção no mercado de trabalho que também varia conforme o perfil da ocupação,

\begin{abstract}
Aquelas ocupações mais voltadas ao contato direto com o público estão mais suscetíveis à exclusão dos negros, ao contrário de posições manuais. Também é forte a hipótese de que quanto mais alta a ocupação está na hierarquia ocupacional, mais refratária à absorção de negros. E de quanto mais alto for nível educacional exigido, maior será a discriminação observada no mercado de trabalho (JACCOUD, 2008, p. 58).
\end{abstract}

Outro fator que deve ser considerado na análise das oportundiades para ambos os grupos é a de que as ofertas de empregos na região que estarmuito restrita e pouco diversificada, concentrada em poucas opções como os abatedouros de aves e frigoríficos da região, o que chamou a atenção à condição de saúde dos entrevistados. Entre os negros, em 7 dos formulários (47\% do total dos sujeitos negros) constava alguma observação das assistentes sociais sobre a condição de saúde dos sujeitos e constava o registro de alguma doença relacionada ao trabalho. As principais queixas relatadas estão relacionadas com a atividade laboral exercida por serem atividades braçais com movimentos repetitivos ou excesso de peso e exercidas em ambiente de trabalho insalubre, muitas em abatedouro de aves.

Dentre esses: 1 é aposentado, mas relata necessidade de trabalhar porque sua renda é insuficiente para se manter, embora não consiga trabalhar porque apresenta diversos problemas de saúde e mal consegue efetuar os afazeres essenciais do cotidiano;2 relataram sérios problemas de saúde, mas continuam trabalhando por não serem assegurados da 
previdência; 2 reclamam que tentaram o benefício BPC mas, não correspondem aos critérios e 2 tiveram o auxílio doença negado por não conseguirem comprovar incapacidade na perícia médica.Enfim, dentre os sujeitos negros, 8 não relataram nenhum problema de saúde, mas, as condições de trabalho que estão expostos já apontam para o risco de desenvolver uma doença ocupacional caso não haja prevenção.

Entre os 18 sujeitos da pesquisa que são brancos: 4 apresentavam algum problema de saúde: 1 situação de saúde mental, na qual o sujeito recebe o benefício BPC e 3 que estavam adoecidos em decorrência do trabalho, desses:2 estavam protegidos pelo auxíliodoença, 1 em reabilitação profissional, e 1 que estava desprotegido pois, não conseguiu provar a incapacidade na pericia médica, mas estava recorrendo judicialmente.

Sobre as demandas por direitos previdenciários apresentados pelos sujeitos aos assistentes sociais, quando procuraram a agência, observa-se uma acentuada diferença entre as apresentadas pelos sujeitos negros e pelos sujeitos brancos, conforme ilustram as tabelas a seguir:

\section{Quadro 1 - Motivo do atendimento - Negros}

\begin{tabular}{|c|l|}
\hline Sujeito 1 & Orientação sobre carteira de passe livre para Pessoa com Deficiência. \\
\hline Sujeito 2 & Orientação sobre aposentadoria por tempo de contribuição. Pedido agendado. \\
\hline Sujeito 3 & $\begin{array}{l}\text { Orientação sobre formas de contribuição para a previdência social como facultativo } \\
\text { (para a esposa que é do lar). }\end{array}$ \\
\hline Sujeito 4 & $\begin{array}{l}\text { Orientação sobre benefício BPC para pessoa idosa do pai (sofreu diversos AVCs que o } \\
\text { deixaram com comprometimento motor e cognitivo) que foi bloqueado. }\end{array}$ \\
\hline Sujeito 5 & $\begin{array}{l}\text { Avaliação social como parte do processo de requerimento do BPC para pessoa com } \\
\text { deficiência. }\end{array}$ \\
\hline Sujeito 6 & Avaliação social como parte do processo de requerimento do BPC para pessoa idosa. \\
\hline Sujeito 7 & $\begin{array}{l}\text { Orientações sobre benefício previdenciário - aposentadoria por idade, aposentadoria } \\
\text { por tempo de contribuição e aposentadoria especial. }\end{array}$ \\
\hline Sujeito 8 & $\begin{array}{l}\text { Orientação sobre a possibilidade de receber o salário-maternidade, pois está no 70 mês } \\
\text { de gestação. }\end{array}$ \\
\hline Sujeito 9 & $\begin{array}{l}\text { Orientação sobre possibilidade de receber Benefício de Prestação continuada - BPC. } \\
\text { Como nunca prestou contribuição ao INSS está impossibilitada de acessar benefícios } \\
\text { previdenciários. }\end{array}$ \\
\hline Sujeito 10 & Requerimento de auxílio-doença. \\
\hline Sujeito 11 & Solicitação de BPC para seu pai. \\
\hline Sujeito 12 & Orientação sobre salário-maternidade. Tem um bebe de 18 dias. \\
\hline Sujeito 13 & $\begin{array}{l}\text { Orientação sobre pensão por morte buscou o INSS para tirar dúvida se corre o risco de } \\
\text { perder seu benefício caso se case novamente. }\end{array}$ \\
\hline Sujeito 14 & $\begin{array}{l}\text { Orientação sobre benefício previdenciário - aposentadoria por idade, aposentadoria } \\
\text { por tempo de contribuição e aposentadoria especial. }\end{array}$ \\
\hline Sujeito 15 & Orientação sobre a contribuição previdenciária. \\
\hline
\end{tabular}

Fonte: Próprias autoras, 2017 
Quadro 2 - Motivo do atendimento - Brancos

\begin{tabular}{|c|c|}
\hline Sujeito 16 & $\begin{array}{l}\text { Acompanhou o esposo na Avaliação Social, como parte do processo de } \\
\text { requerimento do BPC para Pessoa com Deficiência. }\end{array}$ \\
\hline Sujeito17 & Atendimento referente ao programa de reabilitação profissional. \\
\hline Sujeito 18 & Orientação sobre critérios de mudança no BPC. \\
\hline Sujeito 19 & Orientação sobre formas de contribuição previdenciária como facultativo. \\
\hline Sujeito 20 & $\begin{array}{l}\text { Orientação sobre formas de contribuição para a previdência social como } \\
\text { contribuinte individual. }\end{array}$ \\
\hline Sujeito 21 & $\begin{array}{l}\text { Orientação sobre formas de contribuição para a previdência social como } \\
\text { facultativo. }\end{array}$ \\
\hline Sujeito 22 & $\begin{array}{l}\text { Informação sobre o benefício de auxílio-doença. Usuário está tentando o } \\
\text { benefício há algum tempo, porém não conseguiu, porque foi barrada na } \\
\text { perícia médica do INSS, como não consegue exercer suas atividades laborais } \\
\text { procurou a agência do INSS para nova tentativa e recorrendo judicialmente. }\end{array}$ \\
\hline Sujeito 23 & Orientação sobre aposentadoria por idade. \\
\hline Sujeito 24 & $\begin{array}{l}\text { Orientação sobre formas de contribuição para a previdência como } \\
\text { contribuinte individual. }\end{array}$ \\
\hline Sujeito 25 & $\begin{array}{l}\text { Solicitação de pensão por morte para os netos, haja vista que a filha da } \\
\text { requerente ter falecido (era segurada da previdência social). }\end{array}$ \\
\hline Sujeito 26 & $\begin{array}{l}\text { Orientação sobre formas de contribuição para a previdência social como } \\
\text { facultativo. }\end{array}$ \\
\hline Sujeito 27 & $\begin{array}{l}\text { Orientação sobre possibilidade da concessão do BPC para a irmã que é } \\
\text { doente. }\end{array}$ \\
\hline Sujeito 28 & Orientação sobre possibilidade de contribuir para a previdência social. \\
\hline Sujeito 29 & Orientações sobre possibilidade de contribuir com a Previdência social. \\
\hline Sujeito 30 & Orientação sobre programa de reabilitação profissional. \\
\hline Sujeito 31 & Orientação sobre formas de contribuição. \\
\hline Sujeito 32 & $\begin{array}{l}\text { Orientação sobre a possibilidade da esposa contribuir com a previdência } \\
\text { social. }\end{array}$ \\
\hline Sujeito 33 & Orientação sobre critérios de manutenção do BPC da esposa. \\
\hline
\end{tabular}

Fonte: Próprias autoras, 2017

Entre os negros, a principal demanda é a informação sobre benefícios, sobretudo, o não contributivo, como o Benefício de Prestação Continuada - BPC. Entre os brancos, a principal demanda foi à informação sobre formas de contribuição para a Previdência social. Os negros, em sua maioria, solicitaram informação sobre formas de inserção nos serviços e benefícios, enquanto, que os brancos solicitaram informações sobre benefícios já adquiridos. Os dados revelam, também, que o acesso ou busca pela informação sobre a inserção na previdência é desproporcional entre os dois grupos. Enquanto, entre os negros a busca por informações de como contribuir para a previdência foi de $14 \%$, entre os brancos foi de $62 \%$; ou seja, caracteriza-se a principal demanda dos sujeitos do grupo dos brancos que procuraram a agência do INSS. 
Entre os brancos: 7 (38,8 \%) tiveram dificuldade no acesso aos benefícios por três motivos: por ter renda familiar per capta acima do critério do benefício requerido; por não aderir ao critério de comprovação de prova pericial; e tempo insuficiente de contribuição. Três, dentre os brancos, tiveram benefício negado; 4 não fizeram tentativa de acesso aos benefícios e 9 não apresentaram nenhuma dificuldade para acessar aos benefícios.

Já, entre os negros: 8 (53,33\%) tiveram dificuldades no acesso aos benefícios. Os principais motivos foram: renda familiar per capta acima do critério do benefício requerido (BPC); não era assegurado da previdência; não possuía tempo suficiente de contribuição; e não conseguiu comprovar incapacidade na perícia médica. Para os negros, o fato de não ser um assegurado da previdência é o principal impedimento para o acesso aos benefícios, para os brancos esse motivo não constou; pois todos que procuraram a agência, ou já eram assegurados ou estavam à procura de informações de como se filiar à previdência.

É possível constantar, com esses dados, que os sujeitos brancos desta pesquisa, estão entre a população branca que contribui com previdência, porque possui mais oportunidades de inserção no emprego formal. E que, quando não estão trabalhando de maneira formal, ainda assim, tem salários compatíveis com a possibilidade de contribuição com a previdência. Por outro lado, entre os sujeitos que são negros essa tendência é menor. Infere-se, aqui, que esse fato ocorre, porque a população negra tem menos acesso à informação sobre formas alternativas de contribuição. Destaca-se que, entre os 15 sujeitos negros que procuraram a agência do INSS, apenas 2 buscaram por essas informações referentes a esta contribuição, enquanto entre os brancos, 18 sujeitos, a maioria (10) buscava por essa informação.

\section{Considerações Finais}

A pesquisa mostrou aspectos que evidenciam a precarização das condições de vida dos trabalhadores que procuram o INSS. Dentre as expressões da questão social que evidenciam essa precarização, as mais evidentes são: a falta de renda; o desemprego; superexploração do trabalho revelada na condição de adoecimento dos sujeitos; a precarização do trabalho tanto nas suas condições, como, nas relações de trabalho, marcadas pelo emprego desprotegido, a oferta restrita de empregos na região e as poucas oportunidades concentradas em empregos precários e mal remunerados.

São dados que desafiam a atuação profissional dos assistentes sociais que têm, entre seus princípios éticos, a universalidade de acesso e ampliação de cidadania; o que pressupõe, 
entre outros aspectos, a gestão política de benefícios previdenciários pautados na equidade. São princípios que remetem à necessidade de considerar as expressões diversas da desigualdade social e, dentre estas, as que se evidenciam nas dificuldades de acesso aos direitos previdenciários. Entre essas, nítidos contornos da desigualdade racial.

A pesquisa foi construída a partir da comparação entre dois grupos raciais (brancos e negros) e revelou que, por mais que sujeitos de ambos os grupos tenham condições de vida muito semelhantes - tais como a condição de classe, de renda e de escolaridade - as diferenças de raça manifestam-se em oportunidades de acesso aos direitos previdenciários, de formas diferenciadas. Isso se revelou pelo acesso ao mercado de trabalho, pela condição de saúde, vínculo empregatício e pela demanda apresentada ao buscar a agência do INSS.

A Política de Previdência, por ser contributiva, a priori, apresenta problemas com relação ao acesso e garantia de direitos para a população negra. Pois, historicamente essa população, além de figurar entre as que compõem taxas de desempregro, têm participação expressiva nos postos de trabalhos precarizados e informais dentre os quais estão o trabalho rural e o doméstico; e as formas de empregabilidade que levaram mais tempo para adquirir direitos previdenciários. Este fato que torna relevante uma investigação sobre a desigualdade racial nessa política. Nesta direção, a pesquisa cujos resultados ora apresentada permite concluir que tal política, por ser contributiva, apresenta dificuldade de acesso e garantia de direitos para a população negra, o que torna relevante uma investigação da desigualdade racial nessa política.

\section{Referências}

CICONELLO, Alexandre. O desafio de eliminar o racismo no Brasil: a nova institucionalidade no combate à desigualdade racial. In: OXFAM INTERNATIONAL (Org.). From poverty to power: how active citizens and effective states can change the world. Londres: Oxfam International, 2008. Disponível em:

<http://homologa1.portaldoservidor.ba.gov.br/sites/default/files/Racismo\%20\%20texto\%20do\%20Peck.pdf>. Acesso em: 10 jan. 2016.

COSTA, Emília Viotti da. Política de terras no Brasil e nos Estados Unidos. In: .$D a$ monarquia à república: momentos decisivos. 7. ed. São Paulo: Fundação Editora UNESP, 1999. p. 169-193.

COSTA, Ricardo Cesar Rocha da. O pensamento social brasileiro e a questão racial: da ideologia do "branqueamento" às "divisões perigosas". Revista África e Africanidades, Quissamã, v. 3, n. 10, ago. 2010. Disponível em: 
<http://www.africaeafricanidades.com.br/documentos/10082010_16.pdf>. Acesso em: 25 set. 2016.

GUIMARÃES, Antônio Sérgio Alfredo. Raça e racismo no Brasil. In: . Racismo e antirracismo no Brasil. São Paulo: Editora 34, 1999. p. 19-67.

IBGE. IBGE divulga renda domiciliar per capita 2015. Disponível em:

<ftp://ftp.ibge.gov.br/Trabalho_e_Rendimento/Pesquisa_Nacional_por_Amostra_de_Domic ilios_continua/Renda_domiciliar_per_capita/Renda_domiciliar_per_capita_2015_20160420. pdf>. Acesso em: 5 dez. 2015.

IBGE. Rolândia. Disponível em: <https://cidades.ibge.gov.br/brasil/pr/rolandia/panorama>. Acesso em: 20 set. 2016.

IBGE. Síntese de indicadores sociais: uma análise das condições de vida da população brasileira. Estudos \& Pesquisas: informação demográfica e socioeconômica, Rio de Janeiro, n. 35, 2015. Disponível em: <https://biblioteca.ibge.gov.br/visualizacao/livros/liv95011.pdf>. Acesso em: 5 dez. 2015.

IPEA. Políticas sociais: acompanhamento e análise, Brasília, n. 22, 2014. Disponível em: <http://www.ipea.gov.br/portal/images/stories/PDFs/politicas_sociais/140930_bps22.pdf>. Acesso em:3 mar. 2016.

JACCOUD, Luciana. Racismo e república: o debate sobre o branqueamento e a discriminação racial no Brasil. In: THEODORO, Mário (Org.). As políticas públicas e a desigualdade racial no Brasil: 120 anos após a abolição. 2. ed. Brasília: Ipea, 2008. p. 45-64.

NEDER, Gizlene. Ajustando o foco das lentes: um novo olhar sobre a organização das famílias no Brasil. In: KALOUSTIAN, Silvio Manoug (Org.). Família brasileira: a base de tudo. São Paulo: Cortez, 1994. p. 26-46.

NEGROS representam $54 \%$ da população do país, mas são só $17 \%$ dos mais ricos. $U O L$ Economia, 4 dez. 2015. Disponível em:

<https://economia.uol.com.br/noticias/redacao/2015/12/04/negros-representam-54-dapopulacao-do-pais-mas-sao-so-17-dos-mais-ricos.htm?cmpid=copiaecola>. Acesso em: 3 mar. 2016.

THEODORO, Mário. A formação do mercado de trabalho e a questão racial no Brasil. In: THEODORO, Mário (Org.). As políticas públicas e a desigualdade racial no Brasil: 120 anos após a abolição. 2. ed. Brasília: Ipea, 2008. p. 15-43. 
Recebido em: 14/05/2018 Aceito em: 24/05/2018 